\title{
Relações de poder no discurso pedagógico/didático
}

\section{Elisa Guimarāes}

Professora titular da Universidade Presbiteriana Mackenzie.

Resumo: Análise centrada no conceito de acontecimento discursivo, entendido como 0 ponto de encontro entre uma atualidade e uma memória, de acordo com a formulaçāo teórica de Pêcheux, visando a buscar, nas marcas discursivas do discurso pedagógico/didático, os traços ideológicos que legitimam as relaçōes de poder.

Palavras-chave: discurso didático; ideologia; educaçāo
Abstract:Analysis centred upon the concept of discursive happening, understood as the converging point between the present time and memory, in accordance with the theoretical ideas by Pêcheux, aiming to identify the ideological traces which legitimate power relations in the pedagogical/didactic discourse.

Keywords :didactic discourse; ideology; education 

Constituem-se como eixo deste ensaio, fundamentado em propostas da Análise do Discurso, questões ligadas ao discurso na sua feição pedagógicodidática, ou seja, na dimensão que se estende em um âmbito mais abrangente, constando de ditames gerais vinculados ao processo educacional ou configurados em preceitos aplicáveis a espaços onde se salientam interesses comprometidos com a ação educativa.

Afunilando propostas do discurso pedagógico, abordaremos aquelas que se apresentam no discurso didático manifestado em sala de aula.

Em Análise do Discurso, o termo "didático" caracteriza tanto um discurso quanto uma situação que se relacione com a transmissão de um saber ou de um saberfazer, ou, em um emprego mais restrito, de um discurso ou de uma situação de ensino e aprendizagem.

Concebido, seja na sua conformação pedagógica, seja na sua intenção didática, o discurso, nessas duas feições, sujeita-se a relações de poder.

São essas coordenadas que, como componentes de um quadro de enunciação, Maingueneau (1987) oncebe como a dêixis fundadora, ou seja, o cenário no qual se vai definir o caráter polêmico do discurso.

Consideremos, a partir desses dados e à luz das propostas da Análise do Discurso, as relações de poder a que vem se sujeitando o discurso pedagógico, comprometido com o que chamamos discurso fundador, assim definido:

Aquele que instala as condições de formação de outros discursos, filiando-se à sua própria possibilidade, instituindo em seu conjunto um complexo de formações discursivas, uma região de sentidos, um sítio de significância que configura um processo de identificação para uma cultura, uma raça, uma nacionalidade (ORLANDI, 1993, p. 124).

Para completar essa definição, acrescentemos o conceito de "acontecimento discursivo", entendido este 
na maneira como Pêcheux o formula, ou seja, o ponto de encontro entre uma atualidade e uma memória $2(1975)$. Concentra-se, portanto, o acontecimento discursivo, no seu aspecto mais geral, no que chamamos discurso fundador, refletido, na perspectiva deste ensaio, no discurso pedagógico.

A produção dos efeitos que atribuímos ao discurso fundador é muito mais do que um reconhecimento de significações que se repetem. O discurso não seria fundador por dizer "alguma coisa" pela primeira vez. Antes, constituise como discurso fundador porque se fixa à maneira de um eixo em torno do qual se desenvolvem outros discursos dentro das mesmas concepções, dos mesmos princípios. Concretiza-se, portanto, nesse particular, o ponto de encontro de uma atualidade e de uma memória recapitulando a concepção de acontecimento discursivo, segundo Pêcheux.

Uma retrospectiva no tocante à história do discurso pedagógico, no âmbito da educação brasileira, permite constatar a presença de discursos manifestando relações de poder propensas a justificar diferenças sociais.

Assim, desde o descobrimento do Brasil, mantêmse os privilégios da classe dominante. Há, por exemplo, no discurso europeu acerca do colonizado, um enaltecimento de suas próprias qualidades, enquanto se sugerem traços de negativa diferença entre os dois discursos - o do colonizador e o do colonizado.

Ao longo do tempo reinstaura-se constantemente esse discurso, numa perene circulação de formulações discursivas constitutivas do discurso fundador. Propôsse, por conseguinte, como modelo o discurso europeu, que não encara o colonizado num mesmo nível de igualdade, bem como não lhe confere a posse de qualidades positivas.

Veja-se, por exemplo, como reflexo dessa visão, um pequeno excerto da carta de Pero Vaz de Caminha a D. Manuel, rei de Portugal, na época do descobrimento:

Gente bestial de pouco saber, e por isso tão esquiva 
Dessa mesma visão apresentam-se imbuídos os discursos educacionais que vêm transpondo os limites das eras. Enfatizam-se as diferenças individuais - estas, nas origens, comprovadas, não em bases científicas, mas pela observação direta dos sujeitos. Marcam-se, assim, os discursos educacionais com o estabelecimento de padrões alicerçados no princípio que considera inferiores aqueles que não se harmonizam com o padrão. Solidificam-se, à luz desses princípios, as formas de dominação ou as relações de poder: assim, por exemplo, no Brasil colônia, a situação dos brancos a quem se facilitava o acesso à cultura dominante, ao lado dos indígenas a quem se impunha a domesticação - por via da catequização servindo esse esquema de ensino diferenciado a interesses políticos e econômicos daquela época.

O período monárquico não alterou muito a situação da educação nacional, já que esta ficou a cargo dos governos provinciais, carentes de recursos financeiros para tal fim. Não houve um projeto para emancipação cultural, pois isso não interessava à elite exportadora dominante. Como conseqüência, a taxa de analfabetismo no final do século XIX era de $70 \%$.

Fatores de natureza econômica forçaram modificações na sociedade. Com o sucesso da lavoura de café, a classe média foi ganhando consistência e exigindo reformulações políticas, tais como a República, a abolição da escravatura, o Positivismo, que defendia o cientificismo e o racionalismo que se propagaram pela educação.

Em 1837, é fundado no Rio de Janeiro o primeiro colégio oficial do Brasil, o Colégio Pedro II, onde estudava a elite pensante e que, por um longo período, foi parâmetro de ensino para todo o país.

A almejada República também não trouxe mudanças significativas para a educação. Após breves buscas para solução de problemas educacionais, acaba servindo aos interesses da classe dominante e abraça o modelo tradicional, elitista, dirigido aos representantes do poder rural que ambicionavam cargos na administração 
pública. A partir daí, seguem-se períodos que repetem a mesma característica: de um lado, esforços contínuos para manutenção de uma estrutura conservadora; de outro, a necessidade inadiável de transformações por pressão de grupos menos favorecidos e necessidades de formação de mão-de-obra habilitada para indústrias.

$\mathrm{Na}$ década de 30 , expandem-se o ensino médio para ricos e o profissionalizante para pobres, objetivando produção de trabalho mais rápida e mais barata para o Estado. A ditadura intensifica, na década de 70, a defasagem entre o sistema educacional e o econômico; há difusão dos estudos superiores, embora por meio de instituições particulares, paradoxalmente destinadas à população de baixa renda, por estar menos habilitada aos vestibulares das universidades públicas, e/ou por se concentrar em regiões menos centrais. Como resultado dessa política educacional, operam-se a eliminação de lideranças políticas e o aniquilamento de participação social. Na década de 90, por pressão do FMI, torna-se obrigatório o ensino fundamental de oito anos. Esse contingente maior de alunos obriga a construção de um maior número de escolas com menos horas de ensino e, portanto, com menos qualidade de ensino. $O$ depauperamento da escola pública e o florescimento da rede privada corroboraram para a perpetuação do processo de elitização do ensino brasileiro.

Como explicar o quadro das diferenças? Várias justificativas tentaram explicá-lo: cada indivíduo é diferente do outro e, em conseqüência, será diferente o rendimento de cada um. Verificou-se, no entanto, que as diferenças não ocorriam apenas entre indivíduos, mas, sobretudo, entre grupos de indivíduos, entre grupos sociais dominados e dominantes. E por que o fracasso escolar estaria concentrado nas classes socioeconomicamente desfavorecidas? Para alguns, as diferenças sociais teriam origem nas diferentes aptidões individuais, ou seja, os mais aptos constituiriam as classes dominantes, enquanto os menos aptos constituiriam as dominadas e 
socioeconomicamente desfavorecidas. Assim, era esperado que alunos advindos de classes desfavorecidas tivessem rendimento baixo; se alguns deles fossem bem dotados, teriam acesso à classe dominante. Ora, se a teoria do dom individual fosse perfeitamente aceitável, também deveriam fracassar nas mesmas proporções os alunos provenientes de classes dominantes.

Levanta-se, então, outra hipótese: as desigualdades sociais seriam a causa das diferenças de rendimento escolar, já que o contexto de um tipo de sociedade permitiria o desenvolvimento de aptidões para o sucesso escolar, enquanto o outro, menos favorecido, além de não o permitir, seria responsável pelos déficits socioculturais. Uma das funções da escola seria tratar dessa "patologia" social, compensando essa "privação cultural".

$\mathrm{Na}$ sociedade moderna, em que o pluralismo cultural se soma à organização capitalista, assiste-se à escola representando a cultura da classe dominante. Assim, os alunos provenientes das classes dominadas, ao ingressar na escola, defrontam-se com padrões culturais que não são os seus. Seu comportamento, seus conhecimentos são avaliados segundo um modelo da classe dominante, constituídos segundo conceitos e informações que lhes são desconhecidos. Sofrem, portanto, um processo de marginalização cultural que os leva ao fracasso, não por serem deficientes, mas por serem diferentes.

Essa realidade aponta para a escola mantendo e perpetuando a estrutura social, a discriminação, garantindo, pois, a hegemonia da classe dominante.

Conclui-se das idéias expostas até aqui que há muito ainda a realizar para transformar a escola - ao invés de lugar de manutenção das relações de poder - em um espaço capaz de atingir a eqüidade social. Este, sim, é o plano ideal de alcance do discurso pedagógico.

E o discurso didático - aquele que se exerce em sala de aula? Como se efetivam aí as relações de poder? É o que passamos a explorar.

Estamos diante de um tipo de discurso no qual os lugares sociais são diferentes. Trata-se de uma estrutura 
de poder bastante complexa, na medida em que compreende vários microuniversos de discurso, que se sustentam em relações intertextuais e interdiscursivas caracterizando-se os diferentes universos de discurso, dentre outros aspectos, por suas estruturas de poder. É um discurso voltado para a formação e a informação, um discurso que se propõe criar e transmitir conhecimentos, gerar uma competência, despertar uma vocação, instaurar uma ética geral e profissional e estabelecer, desse modo, um sistema de crenças nesses propósitos.

Encara-se nesse discurso o professor detentor do conhecimento, do poder, controlando a situação, sem, no entanto, embargar o encontro de vozes. Não há aí um sujeito produtor do discurso, mas várias vozes. As palavras vêm sempre carregadas, ocupadas por outros discursos, ou seja, verifica-se o interdiscurso atravessando o intradiscurso.

Não se pode apreender, no discurso, um sujeitoem-si, mas sim um sujeito constituído socialmente, pois não são as intenções que contam, já que as convenções Konstituem parte fundamental do dizer (ORLANDI, 1988, p. 29)

Um sujeito, ao enunciar uma espécie de "ritual social da linguagem", implícito, partilhado pelos interlocutores. $\mathrm{Na}$ instituição escolar, o enunciado produzido pelo professor é colocado em um contrato que lhe credita o lugar de detentor do saber. O contrato de fala que o liga ao aluno não lhe permite ser "não-possuidor do saber"; ele é antecipadamente legitimado. (CHARAUDEAU; MAINGUENEAU, 1987, p. 55)

Entende-se que a posição da escola é indissociável da posição assumida pelo professor para exercer seu papel de educador, na medida em que o discurso da escola é edificado pela prática discursiva de seus docentes.

O professor legitima a informação que ele passa ao aluno, submetendo-se à autoridade do cientista 
enquanto a assume e a transfere para si, ficando, assim, impessoal, difusa a autoridade. Assim, é na conformação do discurso didático que se apreende um sujeito iludido no sentido de ser ele próprio a origem do seu discurso, desconhecedor, no entanto, de ser perpassado pela ideologia. Há um clima de dominação do discurso fundador sobre aquele que tende a ressignificá-lo, ainda que se trate de um espaço onde se pretende a desestabilização da dominação, como seja o espaço da escola.

Não obstante, o professor conceber a educação como um instrumento eficaz para a conquista da eqüidade social, a instituição escolar - mantenedora do discurso dominante - perpetua as relações de poder no traçado do discurso do sujeito-professor.

A sala de aula é um espaço institucional, e a instituição tem implicações nem sempre totalmente louváveis. Ela vigia e controla o espaço pedagógico ritualizando-o. As ordens do professor não só não são exteriores àquilo que ensinam, como também não se lhe acrescentam. A ordem incide sobre ordens - as ordens do sistema de ensino, as regras de um campo disciplinar, enfim, as normas de uma língua vernácula (MARTINS, 2002).

O conhecimento da lógica própria do social, e neste caso do sistema escolar, leva-nos a reconhecer o transmissor de "palavras de ordem" que é o professor.

Gostaríamos, no entanto, nós, professores, de não ser o sujeito sagrado/consagrado que acadêmica e efetivamente somos. Longe, portanto, de nós a intenção de produzir, na sala de aula, um espaço autônomo arrancado às leis daquilo que Pierre Bordieu (1980) chama de mercado, que compreende não apenas o universo curricular explícito e verbalizado na escola, mas ainda a vasta série de componentes da vida escolar.

Como professores-examinadores, temos de atribuir notas e avaliar os nossos alunos, uma vez que não podemos dissociar-nos das condições sociais de sua produção, e estas não autorizam ilusões desmedidas. Quando é o 
próprio espaço de uma sala de aula que é solidário de toda a instituição escolar, é toda a estrutura social que está presente em cada interação.

Madureira Pinto (s/d) sintetiza bem esse ponto de vista ao afirmar que o sistema escolar impõe o arbitrário cultural - definido, em última análise, pelas relações de força entre as classes sociais - em vez de reproduzir funcionalmente o subsistema cultural.

Em suma, o ator social (no caso, o professor) é um instrumento de reprodução social, que legitima uma posição social, na exata medida em que procura concretizar, na sala de aula, no campo científico, e no campo das idéias em geral, os seus interesses pedagógicocientíficos - do que resulta um efeito de reprodução social.

Quer isto dizer que o professor está sujeito ao jogo dialógico do discurso do conhecimento em geral, repetindo ordens quando supõe apenas afirmar a liberdade. A lição em sala de aula comporta, pois, uma natureza híbrida: produto de uma herança - do discurso fundador vivem-se constrangimentos locais conflitivos, constituindo uma prática de adaptação ao processo temporal ou ao encontro da atualidade com a memória, tomada a expressão de empréstimo a Pêcheux.

Para concluir: embora a cultura se coloque ao alcance de todos, essa democratização é relativa, pois a escolarização não é uniforme, haja vista as escolas que atendem ricos e pobres de modo diferenciado e seletivo. A cultura passa a representar uma modalidade de cultura política e de intervenção social.

Por sua vez, o discurso - tanto na sua forma pedagógica, quanto na sua intenção didática - supõe uma proposta: a de transformar a sociedade por meio da educação. A concretização desse ideal exige, no entanto, uma profunda mudança política, nas concepções, no ideário da população e de suas lideranças, no que diz respeito à sociedade que se pretende construir e ao modelo de educação que pode ser um dos instrumentos dessa construção. 
Tem-se, pois, como necessária a formação para uma prática pedagógica transformadora que rompa com a circularidade do discurso oficial e faça surgir uma ação coletiva realmente inovadora. 


\section{Referências}

BOURDIEU, J. El mercado lingüístico. Questions de sociologie. Paris: Minuit, 1980.

CHARAUDEAU, P.; MAINGUENEAU, D. Dicionário de análise do discurso. São Paulo: Contexto, 2004.

MAINGUENEAU, D. Novas tendências em análise do discurso. Campinas: Pontes, 1987.

MARTINS, Moisés de Lemos. A linguagem, a verdade e 0 poder. Lisboa: Fundação Calouste Gulbenkian/Fundação para a Ciência e a Tecnologia, 2002.

PÊCHEUX, M. Lês vérités de la palice. Paris: Maspero, 1975.

PINTO, J. Madureira. Para um encontro entre a sociologia e a semiótica. Da semiótica. Lisboa: Veja, s/d.

ORLANDI, Eni (Org.). Sujeito e texto. São Paulo: Educ, 1988.

ORLANDI, Eni. O discurso fundador: a formação do país e a construção da identidade nacional. Campinas: Pontes, 1993. 